\title{
A EDUCAC̣ÃO INdÍGENA NOS CONFINS DA AMÉrICA PORTUGUESA: Projetos, esperanças e conflitos (Rio Grande do Sul, século XVIII)
}

Elisa Frühauf

\section{GARCIA}

(D) elisagarcia@id.uff.br

Universidade Federal

Fluminense, Niterói, RJ, Brasil

The education of Native peoples in the borders of Portuguese

America: projects, hopes, and conflicts (Rio Grande do Sul, eighteenth century)

\section{RESUMO}

O artigo analisa a educação dos índios no período pombalino, com ênfase na experiência do atual estado do Rio Grande Sul. Baseado fundamentalmente em fontes primárias, discute as diferentes escalas de recepção das leis promulgadas pela Coroa portuguesa, abarcando as intenções da corte, a mediação dos vice-reis a partir do Rio de Janeiro e o poder local exercido pelas câmaras. Inclui ainda as experiências indígenas que foram potencializadas ou obstruídas de acordo com as vontades políticas vigentes. Através da análise das instituições de ensino criadas para tal fim, assim como de fragmentos de trajetórias pessoais de índios que foram enviados ao Rio de Janeiro para aprofundarem seus estudos, demonstra-se como a educação dos nativos fazia parte de um projeto colonial em constante disputa e transformação.

Palavras-chave: educação indígena; período pombalino; aldeia dos Anjos.

\begin{abstract}
The article analyzes the education of Native peoples during the Pombaline period, focusing on the case of Rio Grande Sul, in the south of Brazil. Based mainly on primary sources, it addresses the different reception levels of laws enacted by the Portuguese Crown. These levels include the court's intentions, the mediation of the viceroys based in Rio de Janeiro, and the local power performed by the city councils. It also covers indigenous experiences that have been enhanced or obstructed according to the policies in force. Through the analysis of educational institutions created for this purpose, as well as fragments of personal trajectories of Indians who were sent to Rio de Janeiro to deepen their studies, the article demonstrates how the education of the Natives was part of a colonial project in constant dispute and transformation.
\end{abstract}

Keywords: Native people education; pombaline period; aldeia dos Anjos (indigenous village). 
educação dos índios foi um aspecto central na construção da sociedade colonial. O tema estava diretamente vinculado à legitimidade da ocupação ibérica do território americano. Como é bem sabido, os assuntos referentes à Igreja na América estavam sob responsabilidade dos respectivos monarcas, devido às concessões papais conhecidas como padroado (BOXER, 1989). E a evangelização, por sua vez, era o mais importante dentre estes assuntos: pressupunha um compromisso de ensinar à população nativa os princípios religiosos, sociais e civis ibéricos. Para os envolvidos na atividade, não era possível dissociar a cristianização dos índios da transformação mais ampla dos seus costumes. Afinal, como destacaram Margarita Menegus Bornemann e Rodolfo Aguirre, "educação indígena e evangelização são dois temas estreitamente ligados" (MENEGUS BORNEMANN; AGUIRRE, 2006, p. 19).

No âmbito mais estrito da escolarização, o estabelecimento de instituições de ensino foi, sobretudo, uma atividade desenvolvida pelos missionários. Os franciscanos fundaram escolas logo após a sua chegada ao México na década de 1520. A mais conhecida, a de Santa Cruz de Santiago de Tlatelolco, estabelecida na década seguinte, destacou-se pela oferta de estudos chamados superiores aos nativos, principalmente o ensino do latim, cujo aprendizado possibilitaria aos alunos um futuro ingresso no sacerdócio. Apesar do sucesso inicial, a escola foi afetada pelas disputas políticas da construção da sociedade colonial, especialmente pelos projetos de manutenção dos índios em uma condição subalterna. Para os defensores de tais projetos, a continuidade dos estudos superiores era uma ameaça à ordem que pretendiam implementar (OLAECHEA LABAYEN, 1992, p. 261-279). A discussão teve ainda outros desdobramentos, como veremos posteriormente.

No Brasil não foi diferente: a instrução escolar iniciou-se juntamente com as atividades evangelizadoras. Em 1549, os jesuítas chegaram à América portuguesa, acompanhando o primeiro governador-geral, Tomé de Sousa. Vinham com o objetivo de instruir e evangelizar, como deixou claro Dom João III: "porque a principal causa que me moveu a mandar povoar as ditas terras do Brasil foi para que a gente dela se convertesse à nossa santa fé católica" '. Os inacianos logo fundaram uma escola onde ensinavam os índios e os filhos dos demais moradores de Salvador. Nos anos seguintes, passaram a atuar em várias regiões, sobretudo em São Vicente, Espírito Santo e Rio de Janeiro.

Em geral, ensinavam-se as primeiras letras. Ocasionalmente, eram ministrados ainda o latim e outros conteúdos mais aprofundados. Em um nível iniciante, o alunado tinha diversas origens. Posteriormente, os índios passaram a receber instrução escolar nos seus respectivos aldeamentos. Já os estudos mais avançados, por sua vez, parecem ter sido restritos às crianças de origem portuguesa (LEITE, 1937; HORNAERT, 2008; LEITE, 2020). Desde os primeiros tempos, desenvolveu-se também no Brasil a discussão então já em andamento na América espanhola: que tipo de educação deveria ser ministrada aos nativos?

Tema controverso na construção da sociedade colonial, a discussão sobre a educação dos índios teve consequências no seu futuro. Foi, porém, sempre inconclusa no mundo ibero-americano. Envolveu agentes variados, incluindo missionários de 
várias ordens, funcionários administrativos ibéricos, particulares e os próprios nativos. Em linhas gerais, a discussão se organizava em duas perspectivas diferentes. Para alguns, os índios faziam parte de um estatuto subordinado e, portanto, não poderiam exercer determinadas funções, especialmente por sua condição de neófitos. Para outros, os nativos deveriam desempenhar as mais variadas atividades, ingressando nas universidades e tornando-se aptos, por exemplo, para o exercício do sacerdócio, especialmente as elites nativas. Tais discussões tomaram força com a consolidação da sociedade colonial e passaram por diversos momentos. Nas decisões e nas iniciativas que prosperavam, incidiam vários aspectos: as políticas das monarquias, as necessidades locais, a influência dos envolvidos, dentre outros (BOXER, 1989).

Não há consenso sobre o tema: as perspectivas variam de acordo com os autores, as regiões e as conjunturas, assim como com as fontes utilizadas. Na Nova Espanha, o acesso dos índios ao ensino do latim, pré-requisito para o exercício do sacerdócio, foi reduzido em alguns momentos e ampliado em outros. Os contrários ao acesso dos índios ao latim alegavam que, caso obtivessem um alto nível de educação, eles poderiam querer interpretar a Bíblia e questionar os princípios da sociedade colonial (OSORIO ROMERO, 1990). Para os favoráveis, porém, os "mistérios da fé" não eram propriedade de ninguém e deveriam ser ensinados aos nativos como uma maneira de "combater a ignorância" (GONZALBO AIZPURU, 2000, p. 116). De forma geral, prevaleceu uma postura restritiva em relação aos índios, embora ela não fosse aplicada de forma absoluta: o mundo colonial possuía vários canais de negociação e formas de mobilidade social. Na Universidade do México, por exemplo, os nativos nunca estiveram completamente ausentes e, por vezes, tiveram trajetórias pessoais de sucesso (MENEGUS BORNEMANN; AGUIRRE, 2006).

Não foi apenas no México que as escolas para os índios foram uma parte inerente da construção da sociedade colonial, principalmente como um mecanismo de relacionamento com as elites nativas. No Peru, as duas instituições mais conhecidas foram as escolas de caciques de Lima e Cusco, administradas pelos jesuítas. Ambas funcionaram como catalisadoras das ambições dos índios, cujos resultados foram variados. Alguns atingiram seus objetivos; muitos viram suas expectativas frustradas ao não obterem o lugar e o respeito social desejados como resultado dos altos investimentos pessoais e intelectuais na educação (ALAPERRINE-BOUYER, 2007).

No Brasil, como mencionado acima, a discussão foi influenciada pelos debates sobre o tema já vigentes na América espanhola. Os contrários à educação dos nativos reproduziram os argumentos lá utilizados: o desprestígio advindo da presença de índios ou pessoas cuja origem poderia ser considerada impura dentro dos critérios do Antigo Regime. ${ }^{2}$ Argumentos sobre a "índole" dos índios reforçavam tais percepções. Para Anchieta, eles não serviam para a vida religiosa, sobretudo pela "fraqueza" em relação às mulheres (HORNAERT, 2008, p. 201). Os favoráveis, por sua vez, também se valiam das razões já apresentadas na América espanhola: a conveniência do conhecimento dos costumes nativos, especialmente a língua, para o melhor desempenho da função evangelizadora. Em linhas gerais, tal argumento beneficiará aqueles identificados como mestiços (HORNAERT, 2008). No emaranhado das classificações étnicas do período 
colonial, porém, nem sempre era possível, ou mesmo desejável na perspectiva dos envolvidos, distinguir claramente uns dos outros.

As concepções sobre a educação dos índios mudaram consideravelmente a partir de meados do século XVIII, quando as medidas reformistas dos impérios ibéricos buscaram promovê-los à condição de súditos iguais aos demais. Na ocasião, foram implementadas uma série de políticas que buscavam extinguir o estatuto subordinado dos índios, abolindo as restrições ao acesso a uma série de cargos e benefícios. No caso do Brasil, a legislação que deveria ser adotada para transformá-los em vassalos iguais aos de origem portuguesa foi sistematizada no Diretório que se deve observar nas povoações dos índios do Pará e Maranhão enquanto Sua Majestade não mandar o contrário (ALMEIDA, 1997). Capitaneado pelo Marquês de Pombal, o projeto pretendia promover uma homogeneização dos súditos, extinguindo paulatinamente a diferenciação jurídica e cultural da população nativa. Um dos elementos fundamentais para atingir tal fim era o estabelecimento de escolas, onde os índios deveriam ser educados dentro dos parâmetros da sociedade colonial. ${ }^{3}$ Neste artigo, analiso a instrução escolar pombalina ministrada aos índios no atual Rio Grande do Sul. Então uma região de fronteira em disputa com a Espanha cujos limites mudavam frequentemente, é aqui abordada pela nomenclatura atual. Tal opção facilita a localização da área pelo leitor não-especializado sem prejuízo da análise histórica.

No início da segunda metade do século XVIII, dois estabelecimentos de ensino foram construídos no Rio Grande do Sul dirigidos à população indígena: uma escola e um recolhimento. Tal população era oriunda das missões do Paraguai, sobretudo as afetadas pelo Tratado de Madri. Como é sabido, o Tratado estipulava a troca da Colônia do Sacramento, da parte de Portugal, por sete dos trinta povos das missões, por parte da Espanha. As tentativas de demarcação do acordado foram tensas e acabaram originando um conflito armado entre os índios e os exércitos ibéricos ocorrido entre 1754 e 1756, conhecido na historiografia como Guerra Guaranítica (GARCIA, 2009; QUARLERI, 2009). Em decorrência do conflito e de negociações com os portugueses, uma parte dos índios afetados pelo Tratado migrou para o território brasileiro no final da década de 1750 e início da seguinte.

A maioria dos migrantes se estabeleceu em uma aldeia chamada Nossa Senhora dos Anjos, cujo território atualmente faz parte da região metropolitana de Porto Alegre (GARCIA, 2009). Nessa aldeia, o Diretório foi implementado de forma sistemática pela coroa portuguesa. Uma parcela menor desses índios foi assentada na aldeia de São Nicolau, em Rio Pardo, onde tal legislação também foi aplicada, porém com menos ênfase.

\section{As escolas nas missões do Paraguai}

Os guaranis que migraram para as aldeias no Rio Grande do Sul tinham uma longa experiência com as atividades escolares. ${ }^{4}$ Nas reduções do Paraguai, assim como em outras regiões americanas, o processo de educação dos índios foi considerado indissociável da atividade evangelizadora, como visto acima. Os missionários estabeleciam escolas à medida que a ocupação daquele espaço se consolidava. Elas 
deveriam atender principalmente aos filhos dos índios chamados principais, mas não exclusivamente. Segundo os relatos, também poderiam ser incluídas as crianças que se destacassem pelo seu talento e aquelas cujos pais solicitassem. $O$ seu funcionamento variou com o tempo e com a diversidade existente na província do Paraguai, que ao todo contava com cerca de trinta reduções. Em geral, havia escolas que ensinavam a ler e escrever, assim como música e dança. No início, os professores eram os jesuítas, mas o pequeno número de missionários acabava limitando a disseminação das escolas. Assim, logo que possível, a função passou a ser desenvolvida também pelos índios, supervisionados pelos padres (BALLESTEROS, 1979; FLECK, 2007).

A opinião dos inacianos sobre os resultados do esforço despendido na educação dos índios variava. Segundo alguns, como o padre José Cardiel, os alunos liam muito bem, habilidade creditada à sua boa memória. ${ }^{5}$ Grande parte dos índios educados nas escolas eram destinados ao governo das missões, que possuíam cabildos compostos pelos nativos e eram responsáveis pela gestão da comunidade. Eles eram frequentemente elogiados pela sua capacidade política, associada ao manejo técnico da língua, tanto escrita quanto falada. Não foram poucos os jesuítas que viram com bons olhos tal capacidade, associando-a ao aprendizado adquirido nas escolas (PERAMÁS, 2004). De acordo com os registros, os guaranis desenvolveram um grande apreço pela escrita, utilizando-a em certos momentos, como ocorreu durante a Guerra Guaranítica, para seus próprios fins (NEUMANN, 2015).

Quando analisavam as habilidades intelectuais dos índios, porém, os jesuítas eram mais severos. Ainda segundo Cardiel, o seu "entendimento" não era dos melhores. ${ }^{6}$ Ao fazer semelhante comentário, apenas emitia uma opinião comum entre os inacianos: os índios eram excelentes copistas e imitadores, mas não se destacavam nas atividades intelectuais. Em geral, eram representados como sujeitos que, apesar de adquirirem as técnicas nas escolas, não possuíam autonomia e deveriam ser supervisionados. Tais considerações foram a base de uma série de análises posteriores, hoje já ultrapassadas, que reproduziam sem maiores questionamentos a percepção dos religiosos de então (HERNANDÉZ, 1913; FURLONG, 1953; BALLESTEROS, 1979).

Nas reduções, meninos e meninas deveriam ser separados tão logo fosse possível. Evitava-se assim qualquer "trato desonesto" e, concomitantemente, promovia-se a sua sociabilidade respeitando a divisão sexual vigente. Segundo Bartolomeu Meliá, apesar de indícios de que em algum momento os jesuítas tivessem implementado escolas para as meninas índias, elas logo foram fechadas e não há notícias de que tenham sido restabelecidas posteriormente (MELIÁ, 1992). As índias deveriam ser educadas, mas nas atividades consideradas características do seu gênero. Sua formação, portanto, não abarcava assuntos como leitura, escrita ou aritmética.

Para as mulheres, havia ainda uma instituição chamada cotiguaçú, que funcionava como uma espécie de recolhimento. Criadas quando as missões já estavam estabelecidas, entre o final do século XVII e início do seguinte, deveriam servir como abrigo para órfãs e viúvas (IMOLESI, 2011; BAPTISTA; WICHERS; BOITA, 2019). Além disso, para lá também seriam enviadas as índias que demonstrassem "algum vício ou fragilidade de sua honestidade e fidelidade", especialmente durante a ausência de seus 
maridos, na esperança de que abandonassem a sua vida "escandalosa" 7 . Em linhas gerais, lá as índias deveriam ser ensinadas a observarem um comportamento condizente com o seu "sexo" e a desempenharem os trabalhos considerados tipicamente femininos (IMOLESI, 2011). Contudo, recentemente alguns autores têm sugerido que o cotiguaçú pode ter tido mais poder político do que até hoje se pensava, exercido especialmente pelas mulheres que conseguiam se projetar na sua estrutura administrativa (BAPTISTA; WICHERS; BOITA, 2019).

Assim, os índios levaram ao Rio Grande uma cultura escolar já desenvolvida nas missões, que terá influência nas instituições de ensino implementadas na aldeia dos Anjos. Ao que tudo indica, elas foram um espaço negociado entre as políticas delineadas pelo Estado português e os quereres dos índios, influenciados pela sua experiência pregressa.

\section{As escolas indígenas no Rio Grande}

Seguindo o estipulado pelo Diretório, na aldeia dos Anjos foi criada uma escola para os meninos índios em 1770, transformada em internato seis anos depois. Para as meninas, foi criado um recolhimento em 1777. Ambos funcionaram por aproximadamente três décadas. As fontes mais importantes para o estudo da escola e do recolhimento são uma série de regras formuladas para orientar o seu funcionamento, elaboradas pelo então governador do Rio Grande do Sul, José Marcelino de Figueiredo. ${ }^{8}$ Essa documentação é de grande valia. Não demonstra tanto como as instituições funcionavam, é verdade, mas revela os objetivos do Estado português.

Para o ingresso no recolhimento, a idade mínima era de seis anos, a máxima de doze, e o número de reclusas não poderia ultrapassar 50 . O seu dia era dedicado às orações, assim como ao aprendizado e exercício dos trabalhos domésticos. Ao nascer do sol, as meninas deveriam se levantar e fazer a higiene pessoal, seguindo para as orações. Após as rezas, as meninas índias iriam para o trabalho, que poderia ser de costura ou de fiação e tecelagem. Então jantariam, teriam um tempo de repouso e retornariam ao trabalho. Depois teriam a ceia, seguida novamente de orações após as quais deveriam se recolher. Segundo o regimento, dois eram os objetivos a serem alcançados com as meninas: que soubessem a língua portuguesa, não sendo permitido o uso do guarani, e que aprendessem todos os serviços domésticos considerados necessários ao bom funcionamento de uma casa. ${ }^{9}$

Parte importante das ideias que orientavam a educação dos índios eram consoantes com as concepções mais amplas vigentes na sociedade colonial sobre o tema. Assim, enquanto na escola os meninos eram ensinados a "falar português, a ler, escrever, rezar e argumentar", as meninas eram iniciadas "na doutrina cristã, e os serviços todos de uma casa". Esse pressuposto de divisão sexual da educação se materializava na sua localização em espaços de natureza diferente, cabendo aos meninos a escola e às meninas o recolhimento.

Os recolhimentos desempenharam vários papéis relativos à vida das mulheres na sociedade colonial. Devido às restrições para existência de conventos na América 
portuguesa, a maioria dos recolhimentos funcionava como um substituto, sendo o espaço para o qual muitas mulheres se dirigiam, ou eram enviadas pelas suas famílias, quando buscavam o estado celibatário (ALGRANTI, 2000). Assim, apesar de não serem conventos, pois as reclusas não faziam votos, o tipo de vida nos recolhimentos era conventual, com o mínimo de comunicação com o mundo exterior (SILVA, 1981). Outros recolhimentos, por sua vez, funcionavam como um local onde deveriam ser recebidas as mulheres menos favorecidas, para serem educadas conforme o papel esperado da condição feminina, recebendo instrução nas primeiras letras e nos trabalhos domésticos. Lá elas seriam preparadas para, no futuro, poderem desempenhar o papel que se esperava de mulheres bem educadas: esposas e mães exemplares, esteio das famílias (DEL PRIORI, 1995; MORANT, 2006). Já a escola, como veremos abaixo, não significava o isolamento dos meninos, pois possuíam maior liberdade para deixá-la durante os dias santos e de folga, assim como para receberem visitas.

Na escola, porém, os meninos também tinham o seu dia rigidamente organizado, com um horário específico para cada atividade. Deveriam acordar pela manhã, fazer a higiene pessoal e almoçar. Após o almoço, permaneceriam das oito às onze na escola, onde aprenderiam a falar, ler e escrever em português, assim como a rezar e argumentar. Jantariam ao meio-dia e teriam descanso até as duas horas, quando retornariam à escola. Lá ficariam até as cinco, exceto no verão, quando entrariam às três e sairiam às seis. Após as aulas fariam suas orações, ceariam e deveriam se recolher. Nas semanas onde não houvesse feriado, teriam um dia de folga. Neste dia, poderiam receber a visita de seus familiares do meio-dia às duas, mas apenas tinham autorização para conversar em português. No dia de folga e nos feriados santos, o mestre poderia escolher entre os seus alunos alguns que considerasse mais aplicados, aos quais concederia licença para irem visitar seus pais. Se algum desses meninos cometesse qualquer tipo de desordem na aldeia, o mestre deveria ser informado, para que não Ihes concedesse mais a licença. Os sábados e os domingos eram destinados às atividades religiosas.

A limpeza e a organização do espaço da escola ficariam a cargo dos meninos que, em sistema de rodízio, deveriam passar, cozinhar, varrer etc. para o coletivo. Durante todo o tempo de permanência na instituição, deveriam ser vigiados para respeitarem rígidos padrões de limpeza e higiene pessoal, e também para que, em hipótese alguma, falassem a língua guarani. No regimento estava previsto castigo para o menino que falasse o guarani e o perdão para quem o delatasse. ${ }^{10}$

No que concerne especificamente aos projetos de ensino das índias, a diferença da sua educação na aldeia dos Anjos e das demais meninas da Colônia está no aprendizado de ler, escrever e contar. Enquanto nos demais recolhimentos essas matérias deveriam ser ministradas (SILVA, 1981), o regimento sobre o recolhimento das índias não previa tais tipos de aprendizado. Todo o tempo era destinado às orações ou ao exercício das lides domésticas, não existindo uma mestra de gramática, como existia para os meninos. Os colonos que comentaram sobre os estabelecimentos de ensino para os índios tampouco fizeram qualquer referência ao estudo da leitura e da escrita no recolhimento. Porém, o Diretório previa que as índias, além de aprenderem 
a doutrina cristã e os "mistérios próprios daquele sexo" 11, deveriam ser ensinadas a ler e escrever, mas não a contar. Se o recolhimento não estava de acordo com o estipulado pelo Diretório, era, porém, consoante com a concepção de ensino existente nas reduções jesuíticas do Paraguai, como visto acima. É possível que nesse aspecto os administradores locais tenham negociado com os índios, mantendo o sistema já existente nas missões, em detrimento de forçar a aplicação estrita do Diretório.

A educação das meninas índias no Rio Grande do Sul estava diretamente vinculada ao projeto dos casamentos mistos. As recolhidas poderiam receber propostas de matrimônio, que seriam comunicadas ao governador, que avaliaria a qualidade do pretendente e, se fosse do seu agrado, permitiria a união e proporcionaria ao casal enxoval e dote. A se dar crédito às regras de funcionamento do recolhimento, as meninas já teriam o enxoval praticamente pronto no momento de seu casamento, pois dedicavam uma parte considerável do seu cotidiano na instituição à sua confecção. É difícil averiguar a realização desses consórcios, pois a ascendência indígena era muitas vezes omitida nos registros matrimoniais. Nas prestações de contas efetuadas pela Real Fazenda constam dotes pagos às índias. No entanto, esses são poucos, deixando a impressão que o governo metropolitano não atingiu a grande quantidade de matrimônios que gostaria.

Uma das principais preocupações do Marquês do Lavradio em relação às índias era a má fama que gozavam junto aos luso-brasileiros, pois era concepção corrente que elas se "prostituíam" logo no início da puberdade, fazendo com que aqueles não quisessem constituir laços familiares com pessoas de semelhante "natureza". Dessa forma, propunha que elas fossem retiradas das suas famílias antes de completarem três anos e entregues a famílias de "boa reputação", para serem criadas como se fossem filhas, adquirindo assim a moral cristã e o aprendizado dos serviços domésticos. ${ }^{12}$ É possível que a difamação levada a cabo contra as índias e índios pelos moradores, como veremos melhor abaixo, tenha influenciado no aparente baixo número de casamentos mistos.

\section{O dilema da língua}

A obrigatoriedade do uso do português foi um assunto bastante conflitivo na aldeia: os índios, principalmente os mais velhos, apenas falavam o guarani e, a se dar crédito à documentação, não manifestavam qualquer vontade de aprender o novo idioma. ${ }^{13}$ Em 1766, o vice-rei do Brasil, Conde da Cunha, comentou sobre as dificuldades em lidar com os índios. Nas suas ponderações, destacou a questão do idioma: desde a sua transmigração para as terras do Rio Grande ainda não tinham aprendido "uma só palavra" do português. ${ }^{14}$ É possível que o Conde da Cunha se expressasse com certo exagero, sobretudo se considerarmos a sua opinião favorável ao retorno dos índios das aldeias dos Anjos e Rio Pardo ao território espanhol, como solicitavam reiteradamente os castelhanos. Na sua visão, o Brasil já tinha índios demais, não precisava ainda ficar com os dos vizinhos... ${ }^{15}$ Seja como for, o tema reaparece cerca de duas décadas depois sem grandes modificações. Em 1784, o governador Sebastião Xavier da Veiga Cabral da Câmara afirmava nunca ter "visto nada igual": os índios 
estavam vivendo há mais de três décadas sob o governo português e, passadas já duas ou três gerações, nem sequer queriam aprender e usar a língua portuguesa. ${ }^{16}$

Possivelmente, a renitência dos mais velhos era um entrave ao pleno sucesso do Diretório neste aspecto: as crianças deveriam ser enviadas aos estabelecimentos de ensino com, no mínimo, seis anos, já tendo adquirido o domínio do guarani enquanto residiam com a sua família. Portanto, se os índios mais velhos apenas falavam guarani e as crianças, após frequentarem a escola, eram bilíngues, é provável que continuassem a utilizá-lo em família. Assim, se dermos crédito às declarações acima, parece que a escola pouco contribuiu para o domínio do português, pois os agentes administrativos não conseguiam visualizar os seus efeitos.

Certamente, as políticas pombalinas não conseguiram extinguir o idioma guarani, como pretendiam. No século XIX, alguns viajantes afirmavam que tinham tido dificuldade para se comunicar com os índios ou mesmo com os moradores de determinadas localidades. Segundo Nicolau Dreys, que esteve no Rio Grande do Sul em meados de 1830, na vila de Rio Pardo, muito próxima da aldeia de São Nicolau, "fala-se mesmo indiferentemente, e quase com a mesma facilidade, a língua portuguesa e a língua indígena" (DREYS, 1990, p.74). Outros viajantes forneceram informações semelhantes, sobretudo aqueles que percorreram a região dos antigos sete povos das missões, que passaram definitivamente para o território português em 1801 (GARCIA, 2009).

A questão, porém, não é tão simples, pois também há indícios de que alguns aprenderam o português, como veremos no item sobre os estudos dos índios no Rio de Janeiro. A língua guarani, além de ser um elemento importante para os aldeados, sobretudo para os geracionalmente mais próximos da experiência nas missões, também estava sujeita a diferentes usos. Provavelmente, era parte da identidade missioneira de muitos, especialmente se lembrarmos que a população da aldeia dos Anjos era mista, ou seja, lá também habitavam colonos de origem portuguesa. Em situações de confronto, não eram raras as ocasiões, se dermos crédito às fontes, em que a língua poderia distinguir uns dos outros. Em outras situações, porém, utilizavam o português segundo as suas conveniências. É provável, portanto, que os comentários um tanto desabonadores sobre a sua fluência no português, para além de revelarem aspectos da relação subjetiva que os índios tinham com o guarani, demonstram também uma disputa política em relação à continuidade das escolas indígenas, que veremos mais adiante.

\section{Os estudos no Rio de Janeiro}

Além desses dois estabelecimentos para o ensino dos índios, a coroa promoveu outras iniciativas visando a sua formação escolar. No início da década de 1770, o vice-rei, Marquês do Lavradio, solicitou ao governador do Rio Grande que enviasse quinze ou dezesseis índios ao Rio de Janeiro para aprenderem determinados ofícios. A iniciativa era uma possibilidade de alguns obterem uma formação mais sólida, pois, ao que parece, a escola da aldeia dos Anjos oferecia uma instrução um tanto aligeirada. Logo que soubessem ler e escrever, contar, rezar a doutrina cristã e falar o português, os estudantes deveriam deixar o colégio para dar lugar a outros. É provável que o 
número de meninos superasse as vagas existentes. Abreviar o tempo despendido na escola era, portanto, uma estratégia para remediar o problema. ${ }^{17}$

Lavradio ordenou que os rapazes se dirigissem à capital bem vestidos e solicitou ao governador que informasse quais eram filhos de principais. ${ }^{18}$ Tal preocupação seguia a prática de valorização e reprodução das elites indígenas, estratégia já utilizada pela monarquia em outras conjunturas (ALMEIDA, 2003). Além disso, não era uma novidade para os índios recém-chegados do Império espanhol, pois os jesuítas também relacionavam o acesso aos estudos à condição política dos pais, como mencionado acima. As ordens do vice-rei foram devidamente cumpridas e alguns dos meninos enviados à capital foram bem sucedidos, como veremos a seguir.

A iniciativa demonstra que o projeto de educação dos índios no período pombalino era mais amplo, pois não se restringia ao âmbito local. Além das escolas nas aldeias, previa ainda a continuidade dos estudos no Rio de Janeiro, oferecendo consideráveis oportunidades aos rapazes selecionados. Compreender esses deslocamentos pode auxiliar a perceber como os índios vivenciaram a legislação pombalina e os diferentes papéis que a educação desempenhou nessa nova conjuntura, que não pode ser reduzida à mera opressão. Afinal, como assinalou Pilar Gonzalbo Aizpuru, "entre a imposição de novas normas e a conservação de tradições, a educação foi simultaneamente instrumento de aculturação e de resistência, agente da modernidade e baluarte da reação" (GONZALBO AIZPURU, 2000, p. 11).

Dois índios enviados do Rio Grande do Sul, um proveniente da aldeia dos Anjos e outro da de São Nicolau em Rio Pardo, prosseguiram com seus estudos e conseguiram ingressar no sacerdócio. Ordenado na década de 1780, José Inácio da Silva Pereira parece ter sido o primeiro padre guarani do Brasil. Além dele, Antônio José de Araújo Silva também se dedicou aos estudos para o sacerdócio. ${ }^{19}$ Ambos estudaram no seminário São José. Fundado em 1739, era então uma das mais prestigiosas instituições de ensino do Brasil, principalmente após a expulsão dos jesuítas em 1759. Pelo seminário São José passaram alguns dos mais importantes intelectuais e políticos da América portuguesa.

Provavelmente, lá teria estudado Basílio da Gama, autor do célebre poema épico "O Uraguai”, impresso em 1769 (GAMA, 2006). A trajetória de Basílio da Gama foi marcada pela expulsão dos jesuítas do Império português e acabou imbricada com a dos índios das missões do Paraguai. Simpatizante da causa dos inacianos, após a expulsão foi a Roma, onde permaneceu por algum tempo. Posteriormente, mudou de ideia: retornou a Portugal e tentou se reaproximar do Marquês de Pombal. Para tanto, escreveu "O Uraguai", inspirado nos conflitos ocorridos na região sul durante as tentativas de demarcação do Tratado de Madri (TEIXEIRA, 1999). No poema, são glorificados os atos do exército português e também, de certa forma, os índios, pois são apresentados como vítimas dos jesuítas. Ironicamente, os filhos desses índios, caracterizados como ingênuos e incapazes, iriam, menos de duas décadas após o conflito, estudar na mesma instituição de renomados luso-brasileiros. Talvez, do próprio autor do poema. 
Apesar de ser um poema onde os índios são representados de maneira romantizada, no "O Uraguai" há uma visão favorável aos guaranis, pois o autor não lhes imputa qualquer responsabilidade pelos conflitos ocorridos na década de 1750 . Não são retratados como inimigos dos interesses de Portugal, mas apenas como vítimas dos inacianos. Pode-se cogitar que, se os dois guaranis que estudaram no seminário São José e passaram a fazer parte, ao menos minimamente, do mundo letrado da América portuguesa, tiveram acesso ao poema. Não é improvável. Nesse caso, a obra Ihes oferecia um lugar dentro do processo histórico da sociedade colonial do Brasil, onde estavam caracterizados de maneira positiva. Sendo assim, para eles, não deveria fazer muita diferença se a sua representação era idealizada ou não, ponto muitas vezes destacado pela historiografia. É possível que a versão de Gama lhes parecesse melhor, pois poderiam utilizá-la para se inserir no mundo do qual passaram a fazer parte.

Além dos seminaristas, havia mais índios das aldeias do Rio Grande estudando no Rio de Janeiro, aprendendo a escrita e a leitura, assim como outros ofícios. Infelizmente, nem sempre é possível vislumbrar com minúcia as suas trajetórias. Sabemos, porém, que eles viajaram conforme o solicitado pelo Marquês do Lavradio: bem vestidos, calçados e munidos dos aparatos considerados necessários à sua vida na capital. ${ }^{20}$ Uma vez lá estabelecido, o grupo continuou sendo assistido pelo governo. ${ }^{21}$

O investimento das diversas instâncias do Estado português na manutenção considerada adequada dos índios no Rio de Janeiro demonstra claramente os esforços despendidos no projeto de educação e de sua transformação em vassalos iguais aos de origem portuguesa. A ênfase na vestimenta, por exemplo, vincula-se a um dos aspectos centrais da sociedade do Antigo Regime, na qual os respectivos estatutos dos seus membros eram demonstrados a partir de quesitos como roupas e formas de tratamento (GODINHO, 1975).

Os sapatos, por exemplo, tinham um forte significado no Império português. A distinção por ele conferida era tamanha que em Angola, no século XVIII, os negros que usavam sapatos eram chamados de brancos, segundo Sérgio Buarque de Holanda (1975). A ênfase atribuída pelos lusitanos ao uso do sapato por parte dos índios está diretamente vinculada à tentativa de mudança de sua condição social, pois esse era um signo considerável na distinção entre livres e escravos. Tais símbolos, porém, mais do que um mero elemento de imposição cultural, parecem ter agradado a muitos guaranis.

Já antes do Tratado de Madri, os índios das missões manifestavam desejos em relação às mercadorias e ao estilo de vida dos colonos de origem europeia. Naquela época, muitos reclamavam do regime comunitário vigente nas reduções, pois não tinham acesso direto ao dinheiro e não podiam comprar roupas e outras mercadorias então valorizadas. Além disso, se dermos crédito às fontes, alguns valorizavam também determinados bens imateriais, cuja definição exata por vezes é complicada, como a "liberdade" e a "diversão", essa frequentemente associada à vida nas cidades (GARCIA, 2013). Décadas depois, quando os jesuítas já haviam sido expulsos, parece que muitos índios deram vazão aos seus desejos. Segundo relatos, eles comprometiam grande parte dos seus recursos comprando bens aparentemente supérfluos, como sapatos e leques. ${ }^{22}$ 
A partir desses registros, é possível considerar que os estudantes estariam valorizando as vestimentas recebidas e a oportunidade de viajar ao Rio de Janeiro. Ao contrário de outros índios, que migraram para várias cidades americanas fugidos ou sem maiores condições de sobrevivência, aqueles receberam os meios necessários para seguir com seus estudos. Através da assistência recebida, eles poderiam não apenas obter uma ocupação razoável na sociedade, mas a sua trajetória possibilitaria também tecer redes de relações pessoais que lhes seriam de grande valia no futuro. Em uma sociedade de Antigo Regime, onde a autoafirmação social e a consequente disputa por privilégios são condicionadas pelo acesso aos signos de prestígio e distinção, pode-se perceber como, nos casos apresentados, os índios estavam no Rio de Janeiro em condições de disputarem espaços. ${ }^{23}$ Tinham assim maiores chances de se estabelecerem, não necessariamente de maneira inferior, no mundo luso-brasileiro. Muitos conseguiram, pois os dois guaranis que estavam estudando no seminário São José foram de fato ordenados.

Quanto aos outros, devido às lacunas nas fontes, é difícil precisar a sua experiência na capital, embora em alguns casos tenha sido possível identificá-los, assim como as respectivas atividades. Miguel Pinto Carneiro estava, em 1773, estudando a leitura e a escrita na escola de Veríssimo Xavier Vieira. A ele foi mandado conceder vestuário, pois se encontrava "falto de roupa" ${ }^{24}$. Outro índio, Cristóvão da Costa Freire, se encontrava aprendendo música na casa de João Álvares Pereira Leite, em 1774. Para Cristóvão, também foi ordenado que fosse concedido todo o necessário para prosseguir nos seus estudos. ${ }^{25}$

O aprendizado de música era considerado uma questão relevante pelo governador do Rio Grande e também pelo Marquês do Lavradio, cujo objetivo principal era a sua execução durante os ofícios divinos na igreja da aldeia dos Anjos. ${ }^{26}$ Não há informação sobre qual instrumento Cristóvão estava aprendendo, mas a música na aldeia parecia ser bem completa. Em 1779, lá havia "um cravista, um rabecão, três rabecas, e oito ou dez vozes que estão aprendendo a outros instrumentos". ${ }^{27} \mathrm{O}$ envolvimento dos índios com a música era antigo, fora relevante nos primeiros contatos com os jesuítas e durante a sua experiência nas missões, quando era uma atividade bastante apreciada pela coletividade (WITTMANN, 2011; FAHRENKROG CIANELLI, 2020). Muitos autores destacaram a sua habilidade como instrumentistas, que se tornou um ofício importante para o seu sustento. No século seguinte, o já citado viajante Nicolau Dreys assinalou a aptidão dos índios para a música. Mencionou ainda sobre um guarani tocador de rabeca, muito requisitado para animar os "bailes da alta sociedade" da cidade do Rio Grande. Para o viajante, tratava-se de um "orfeu dos matos" (DREYS, 1990, p. 75).

Dentre os índios que foram enviados ao Rio de Janeiro para continuarem com a sua formação, havia ainda os que se dedicavam à "arte da cirurgia". Em 1773, Pascoal Baylão e Nicolau da Costa estavam praticando-a no hospital militar. Tal como nos casos citados acima, as suas necessidades foram providas pela Fazenda Real, principalmente a vestimenta. ${ }^{28}$

Considerar a vida dos guaranis enviados ao Rio de Janeiro é bastante complicado, pois as informações sobre o tema são lacunares, embora algumas questões possam 
ser colocadas. Primeiramente, as fontes sobre o seu deslocamento à capital e a respeito da sua vida uma vez lá estabelecidos apontam para quão diversa foi a sua trajetória na sociedade colonial portuguesa. Os guaranis que estavam estudando no Rio de Janeiro estão bem distantes das afirmativas genéricas ainda encontradas na bibliografia disponível, segundo as quais os índios que vieram das missões foram integrados de maneira "marginal e inferior" na sociedade do Rio Grande do Sul. Os estudantes receberam amparo do governo português justamente pela sua condição indígena, gerando um descontentamento considerável da elite local, que se sentiu prejudicada por tais medidas, conforme veremos no próximo item.

É importante destacar também que esses estudantes não devem ser considerados índios "destribalizados", se tomados como aqueles que, por motivos diversos, se desvincularam dos seus grupos e passaram a ter uma trajetória individual, em oposição à anterior, marcada por sua condição coletiva. Nos casos relatados, eles têm, sem dúvida, uma trajetória pessoal. No entanto, é possível considerar que permanecem tendo um vínculo com a sua origem, pois a oportunidade de estudar no Rio de Janeiro Ihes foi concedida justamente porque eram índios das aldeias pombalinas estabelecidas no Rio Grande do Sul. Em um caso, o do padre José Inácio da Silva Pereira, sabemos que o pertencimento à comunidade guarani foi um ponto considerado positivo na sua ordenação. Entre as qualidades ressaltadas, constava sua fluência no idioma nativo, ainda necessário na administração dos sacramentos aos aldeados. ${ }^{29}$ Era um indicativo, portanto, que ele trabalharia com paroquianos guaranis.

Os casos dos índios que se encontravam no Rio de Janeiro dando seguimento à sua formação geraram situações nas quais os guaranis passaram a ter os seus interesses enraizados na América portuguesa. Ao contrário de outros contextos, nos quais alguns índios faziam a sua vida entre os dois domínios ibéricos, esses estavam integrados na sociedade colonial, na qual tinham interesses a zelar (GARCIA, 2009). É possível que tenham efetivamente servido aos objetivos buscados pela política indigenista pombalina. Não estavam certamente "transformados" em vassalos iguais aos demais colonos, pois eram distinguidos enquanto índios e era por essa distinção que gozavam de privilégios. Estavam, no entanto, inseridos na sociedade colonial e, ao terem acesso a uma posição de relativo prestígio, demonstrada entre outros aspectos pelas vestimentas, deveriam servir de modelo aos demais aldeados no Rio Grande. A questão principal a meu ver, porém, não é essa, mas sim em que medida através das políticas pombalinas os índios serviam também aos seus próprios interesses, os quais não eram sempre antagônicos aos do governo português.

Peter Gow, em estudo sobre os piros contemporâneos do Peru, expõe que o grupo por ele estudado não estabelece um vínculo direto com os seus ancestrais como um mecanismo de identificação. Ao contrário, se apresentam enquanto pessoas de "sangue misturado", que valorizam para a sua auto-identificação a escola e os títulos de terras, fazendo inclusive uma diferenciação entre eles, os civilizados, e os seus ancestrais, identificados como aqueles que viviam na floresta. Para o autor, tal diferenciação no que se refere aos seus ancestrais não se dá em relação a um passado "idílico", mas sim tendo como referência os processos de escravização e espoliação sofridos nas 
suas relações com os "brancos”. Assim, para o grupo estudado, o significado de ser civilizado é poder gozar de certas prerrogativas, sendo a principal delas a possibilidade de gerir-se de acordo com os valores próprios da comunidade (GOW, 1991).

Os rumos de grande parte dos índios que estavam estudando no Rio de Janeiro são desconhecidos. Provavelmente nem todos tiveram sucesso, pois o acesso à instrução aumenta as chances, mas não garante uma boa colocação profissional. De qualquer forma, a educação formal recebida, assim como os contatos e o aprendizado da dinâmica de funcionamento da sociedade colonial, provavelmente, serviram ao conjunto dos aldeados. Esses conhecimentos deveriam garantir-lhes certo grau de autonomia e serviram de instrumento quando necessitaram defender os seus interesses contra atitudes dos colonos e de agentes da monarquia consideradas lesivas. É sabido, por exemplo, que os aldeados acionaram instâncias locais e imperiais através de documentos escritos, para cuja redação foram necessários conhecimentos não apenas do português formal, mas também dos meandros burocráticos do Império português (GARCIA, 2009). É possível supor que os membros da comunidade que receberam uma educação formal foram decisivos nessas ações.

Provavelmente, foi devido a uma trajetória de acúmulo de conhecimento e relações dentro da sociedade colonial que eles foram capazes de garantir alguns direitos mesmo depois do desinteresse estatal em manter as aldeias, pois tanto a dos Anjos quanto a de São Nicolau sobreviveram à extinção do Diretório, em 1798. Além disso, ambas enfrentaram antagonistas poderosos: os colonos estabelecidos na região, que não pouparam críticas ao projeto pombalino, sobretudo quanto à educação dos índios.

\section{A oposição local ao projeto pombalino}

Os projetos da coroa não foram bem recebidos por parte significativa dos moradores do Rio Grande. Eles argumentavam que os índios eram de natureza indócil e incapazes para os trabalhos intelectuais. Seriam mais úteis, a si e ao Estado, se empregados nas lides manuais. Os colonos geralmente não se opunham frontalmente às diretrizes governamentais. Louvavam as iniciativas de "civilização" dos índios, mas expunham a sua descrença na mudança da condição dos nativos. Alguns expuseram claramente os seus incômodos em relação ao projeto de educação dos índios. Na época, não havia escolas estabelecidas no Rio Grande: o acesso à educação estava restrito a algumas pessoas, cujos pais podiam pagar professores particulares. Diante disso, o investimento nas escolas para os índios pareceu um desperdício para muitos.

Os argumentos apresentados pela oposição, capitaneada pela elite local, foram sistematizados por Francisco Bettamio em um relato sobre o Rio Grande escrito na década de 1780. Após fazer uma breve descrição dos estabelecimentos para o ensino dos índios (a escola e o recolhimento), sugere que os recursos lá aplicados seriam muito melhor aproveitados se empregados na educação em outras localidades, dirigida à população de origem portuguesa. No raciocínio de Bettamio, a questão era simples: os índios não tinham capacidade de aprender, pois não eram "muito superiores aos animais". Para corroborar as suas ideias, informa existirem poucos rapazes na aldeia capazes de escrever e contar. E, nesses poucos casos, ainda o faziam mal. Com 
tal informação, Bettamio julgava apresentar uma prova cabal da malversação dos recursos da Fazenda Real. Os índios, pela sua "natureza", deveriam ser instruídos no aprendizado de ofícios mecânicos, nos quais teriam mais serventia do que nos trabalhos intelectualizados. ${ }^{30}$

No decorrer do seu relato, ao sugerir as melhorias a serem realizadas no Rio Grande, Bettamio sempre conta como certo o uso do trabalho dos índios em ocupações de baixo valor social, como o corte de árvores, o transporte de madeira, a construção de obras públicas etc. Defende que eles deveriam ser empregados nessas tarefas para se sustentarem, diminuindo as despesas para a Fazenda Real, e também porque esse tipo de trabalho era o que mais se coadunava à sua natureza. Após desenvolver sua linha de raciocínio, conclui: "empregados nestes trabalhos os índios, que melhores estudos haverá para eles?” ${ }^{11}$.

As opiniões correntes sobre as índias, por sua vez, não eram melhores. Como já mencionado, elas deveriam ser educadas para desempenharem o papel de boas esposas e mães exemplares. A expectativa dos legisladores era transformá-las em cônjuges em potencial dos portugueses, favorecendo a política da homogeneização da população através dos casamentos mistos. Para os detratores do Diretório, isso não passava de vã esperança: nem os portugueses gostariam de casar com as índias, nem elas algum dia seriam algo próximo do modelo de virtude feminina então vigente. Como já mencionado acima, afirmavam que elas se "prostituíam" logo no início da puberdade e que os lusitanos não estavam dispostos a constituir laços matrimoniais com pessoas desta "natureza".32 O próprio vice-rei, Luiz de Vasconcelos e Souza, reconhecia as dificuldades de tais casamentos: era necessário o pagamento de bons dotes aos eventuais pretendentes, pois os portugueses, "só obrigados do interesse se sujeitarão a recebê-las". ${ }^{3}$

Todo um arsenal era movido contra as índias: eram mulheres perniciosas e lascivas, levavam a luxúria por onde passavam. Para o já mencionado Francisco Bettamio, elas eram perigosas: serviam de destruição não apenas aos "nacionais", mas também aos próprios índios. Sugeria que fossem alugadas para o serviço dos moradores. Mas na sua visão, não tinha jeito, tanto as mulheres quanto os homens, a despeito de todo o esforço empregado na sua educação, continuavam vivendo na mais absoluta "ignorância”, não tendo, principalmente, os padrões de comportamento sexual "civilizado", deixando-se levar pelo que Ihes "convidava o apetite lascivo". ${ }^{34}$

Assim, tal como em outras conjunturas, não foi sem encontrar uma resistência bem articulada que os projetos de educação dos índios e promoção de sua equiparação social foram aplicados. Os argumentos levantados pelos antagonistas reatualizavam antigas percepções sobre o tema, algumas utilizadas já no século XVI, como visto acima. A falta de originalidade, claro, não era um problema para os moradores: eles não estavam preocupados com isso. Seu objetivo era utilizar, segundo as suas conveniências, as concepções pejorativas existentes sobre os índios para assim convencer a monarquia a desistir dos seus intentos e ainda afastá-los da região.

Para tanto, utilizaram a principal instância do poder local: a câmara. Já no final da década de 1760, os estancieiros solicitaram a transferência dos índios aldeados em 
Viamão para o norte do rio Tramandaí, onde poderiam ter as suas propriedades e criarem o seu gado. ${ }^{35}$ Poucos anos depois, em 1771, os oficiais da câmara do Rio Grande de São Pedro escreveram uma carta ao rei onde novamente era solicitada a retirada dos índios de Viamão, mas desta vez sugeriam que fossem enviados para mais longe. Propunham o seu aldeamento em Santa Catarina. Segundo as queixas apresentadas, os aldeados cometiam roubos de gado e acabavam prejudicando a produção das estâncias da região. ${ }^{36}$ Não satisfeita, a câmara ainda tentou em vários momentos se apropriar dos bens da aldeia dos Anjos. Como em 1778, por exemplo, quando a câmara estava tentando arrematar o açougue da aldeia dos Anjos sem a permissão do governador. Ele recorreu ao vice-rei, Marquês do Lavradio, cuja resposta à câmara foi taxativa: não poderia proceder de tal maneira, pois assim contradizia ao Diretório dos índios. ${ }^{37}$ Os moradores jogaram pesado contra as medidas que beneficiavam os índios e sofreram algumas derrotas, pois a coroa frequentemente se posicionou a favor dos aldeados. No entanto, poucas décadas depois a conjuntura seria outra e os índios já não gozariam da força política que tiveram na América portuguesa na segunda metade do século XVIII.

\section{Conclusão}

Na virada do século XVIII para o XIX, algumas modificações alteraram a vida dos índios das aldeias, comprometendo inclusive a continuidade das instituições de ensino e o investimento na sua formação. A conjuntura política portuguesa havia mudado, a legislação pombalina fora revogada e, no caso específico do Rio Grande, a situação na fronteira com o império espanhol também era outra. Alegando o baixo número de estudantes, a escola e o recolhimento da aldeia dos Anjos foram fechados.

A história da educação dos índios na América ibérica, macro contexto no qual se inserem as iniciativas analisadas neste artigo, não é linear. Ela esteve imbricada com uma série de aspectos políticos, que se associavam aos diversos projetos dos agentes com interesses na sociedade colonial. Afinal, estava em jogo o estatuto dos índios e, consequentemente, o tipo de educação que eles deveriam receber.

Na segunda metade do século XVIII, o Diretório dos índios, ao tentar modificar o estatuto subordinado dos nativos, elegeu a educação como um dos principais meios para atingir tal fim. O seu funcionamento, porém, não foi tão inovador quanto pretendia. A legislação, assim como a sua aplicação, combateu frontalmente o uso das línguas nativas, mas as valorizou quando foi conveniente. O já mencionado padre guarani José da Silva Pereira, provavelmente possuía uma boa formação, mas a sua condição de conhecedor da língua guarani foi destacada como um ponto positivo na sua ordenação. A prática remonta aos primórdios da discussão sobre a educação indígena, quando, como vimos na introdução, o domínio dos idiomas nativos era o principal argumento dos defensores do clero indígena.

A partir da perspectiva da coroa, porém, em parte os resultados esperados com a educação foram atingidos. Certamente, muitos índios enraizaram os seus interesses no Brasil, tornando-se súditos da monarquia portuguesa. As condições oferecidas pela legislação pombalina, quando muitas vezes os governantes coloniais se posicionaram 
ao lado dos aldeados contra os interesses dos colonos, não significavam um apreço especial pelos índios. Ao contrário, tratava-se de uma opção estratégica: em um contexto de disputa acirrada com a Espanha pelo território fronteiriço, os índios poderiam optar pela mudança de vassalagem, escolhendo a que mais benefícios Ihes traria. Assim, segundo o próprio Marquês de Pombal, eles deveriam ser bem tratados, para "se unirem declaradamente a nós contra os castelhanos seus cruéis opressores". ${ }^{38}$

A educação, naquele contexto, deveria servir a um objetivo específico: transformar os índios em vassalos portugueses. Em alguns casos, tais políticas foram bem sucedidas. Quanto aos índios, também houve situações em que eles foram beneficiados. Porém, as promessas feitas na ocasião da sua migração para o Rio Grande nem sempre se cumpriram nas aldeias. Além disso, eles encontraram um ambiente claramente hostil à sua integração na sociedade e à sua equiparação com os súditos de origem portuguesa. $\mathrm{Na}$ ocasião, determinados aspectos presentes desde as primeiras discussões sobre a educação dos índios poderiam ser encontrados nos argumentos contrapostos por vários segmentos sociais, oscilando entre a defesa da sua plena capacidade e a tentativa de manutenção da população indígena em uma posição subalterna. Em vários momentos, alguns propuseram a educação como forma de mudança, em maior ou menos intensidade. Outros se posicionaram abertamente contra qualquer tipo de instrução. Pelo visto, porém, todos concordavam que a escolarização empoderava os índios, facultando-lhes o acesso aos símbolos necessários à compreensão e intervenção no mundo em que viviam.

\section{Referências}

ALAPERRINE-BOUYER, M. La educación de las elites indígenas en el Perú colonial. Lima: IFEA-Instituto Riva Agüero, 2007.

ALGRANTI, L. "Honra, devoção e educação: a vida nos conventos e recolhimentos femininos", Oceanos, Lisboa, n. 42, abril/junho, 2000.

ALMEIDA, M. Metamorfoses indígenas: identidade e cultura nas aldeias coloniais do Rio de Janeiro. Rio de Janeiro: Arquivo Nacional, 2003.

ALMEIDA, R. O Diretório dos índios: um projeto de civilização no Brasil do século XVIII. Brasília: Editora da UnB, 1997.

APOLINÁRIO, J. Os akroá e outros povos indígenas nas fronteiras do sertão. Políticas indígena e indigenista no norte da capitania de Goiás, atual Estado do Tocantins. Século XVIII. Goiânia: Kelps, 2006.

BALLESTEROS, J. La educación jesuítica en las reducciones de guaraníes. Paraná: Universidad Nacional de Entre Ríos, Facultad de Ciencias de la Educación, 1979.

BAPTISTA, J.; WICHERS, C.; BOITA, T. "Mulheres Indígenas nas Missões: patrimônio silenciado", Revista Estudos Feministas, 27(3):e56150, 2019. 
BOCCARA, G. "Mundos Nuevos en las Fronteras del Nuevo Mundo: Relectura de los Procesos Coloniales de Etnogénesis, Etnificación y Mestizaje en Tiempos de Globalización", Mundo Nuevo Nuevos Mundos, 2000.

BOXER, C. A Igreja e a Expansão Ibérica (1440-1770). Lisboa: Edições 70, 1989.

DEL PRIORI, M. Ao sul do corpo: condição feminina, maternidades e mentalidades no Brasil Colônia. Rio de Janeiro: José Olympio, 1995

DOMINGUES, Â. Quando os índios eram vassalos: colonização e relações de poder no Norte do Brasil na segunda metade do século XVIII. Lisboa: Comissão Nacional para as Comemorações dos Descobrimentos Portugueses, 2000.

DREYS, N. Notícia descritiva da província do Rio Grande de São Pedro do Sul [1839]. Porto Alegre: Nova Dimensão/ Ed. da PUCRS, 1990.

ELIAS, N. A Sociedade de Corte. Investigação sobre a sociologia da realeza e da aristocracia de corte. Rio de Janeiro: Jorge Zahar, 2001.

FAHRENKROG CIANELLI, Laura. Los “indios cantores” del Paraguay: prácticas musicales y dinámicas de movilidad en Asunción colonial: siglos XVI-XVIII. Buenos Aires: SB, 2020.

FLECK, E. "A educação jesuítica nos Sete Povos das Missões (séculos 17-18)", Em Aberto, v.21, n.78, p.109-120, dez.2007.

FURLONG, G. Historia y bibliografía de las primeras imprentas platenses. Buenos Aires: Guarania, 1953.

GAMA, J. O Uraguai [1769]. Rio de Janeiro: Record, 2006.

GARCIA, E. "Dimensões da liberdade indígena: missões do Paraguai, séculos XVIIXVIII”, Tempo, vol.19. n.35, jul-dez. 2013.

GARCIA, E. "Os índios e as reformas bourbônicas: entre o ‘despotismo' e o consenso”. In: AZEVEDO, C.; RAMINELLI, R. História das Américas: novas perspectivas. Rio de Janeiro: Editora FGV, 2011.

GARCIA, E. As diversas formas de ser índio: políticas indígenas e políticas indigenistas no extremo sul da América portuguesa. Rio de Janeiro: Arquivo Nacional, 2009.

GODINHO, V. Estrutura da antiga sociedade portuguesa. Lisboa: Arcádia, 1975.

GONZALBO AIZPURU, P. Historia de la educación en la época colonial: el mundo indígena. México: El Colegio de México, Centro de Estudios Históricos, 2000.

GOW, P. Of Mixed Blood. Kinship and History in Peruvian Amazonia. Oxford: Clarendon Press, 1991.

HERNANDÉZ, P. Misiones del Paraguay: organización social de las doctrinas guaraníes da la Compañía de Jesús. Barcelona: Gustavo Gili, 1913. 
HOLANDA, S. Caminhos e fronteiras. Rio de Janeiro: José Olympio, Departamento de Cultura da Guanabara, 1975.

HORNAERT, E. (et al.). História da Igreja no Brasil: ensaio de interpretação a partir do povo: primeira época, Período colonial. Petrópolis, RJ: Vozes, 2008.

IMOLESI, María Elena. "El sistema misional en jaque: la reclusión femenina en las reducciones jesuíticas de guaraníes”, Anos 90, v.18, n.34 (2011).

LEITE, B. "Fábrica de intelectuais. O ensino de Artes nos Colégios jesuíticos do Brasil, 1572-1759”, História Unisinos, 24 (1), Janeiro/Abril 2020, pp.21-33.

LEITE, S. “As primeiras escolas do Brasil”. In: Páginas de história do Brasil. São Paulo, Rio de Janeiro, Recife: Companhia Editora Nacional, 1937.

LOPES, F. Em nome da liberdade: as vilas de índios do Rio Grande do Norte sob o Diretório Pombalino no século XVIII. Rio de Janeiro: PUBLIT, 2015.

MENDONÇA, M. Século XVIII, século pombalino no Brasil. Rio de Janeiro: Xerox do Brasil, 1989.

MENEGUS BORNEMANN, M. \& AGUIRRE, R. Los indios, el sacerdocio y la Universidad en Nueva España, siglos XVI-XVIII. México, D.F.: Plaza y Valdés; Universidad Nacional Autónoma de México, Centro de Estudios sobre la Universidad, 2006.

MELIÁ, B. La lengua guaraní del Paraguay: historia, sociedad y literatura. Madri: MAPFRE, 1992.

MORANT, I. (dir.). Historia de las mujeres en España y América Latina. Vol.II: “El mundo moderno". Madri: Cátedra, 2006.

NEUMANN, E. Letra de índios: cultura escrita, comunicação e memória indígena nas Reduções do Paraguai. São Bernardo do Campo, SP: Nhanduti Editora, 2015.

OLAECHEA LABAYEN, J. “El clero indígena”, In: BORGES, P. (dir.). Historia de Ia Iglesia en Hispanoamerica y Filipinas. Madri: Biblioteca de Autores Cristianos, 1992.

OSORIO ROMERO, I. La enseñanza del latín a los indios. México, D.F.: Universidad Nacional Autónoma de México, Instituto de Investigaciones Filológicas, Centro de Estudios Clásicos, 1990.

PERAMÁS, Josep Manuel. Platón y los Guaraníes [1793]. Assunção: Centro de Estudios Paraguayos “Antonio Guasch”, 2004.

POLONI-SIMARD, J. "Historia de los indios en los Andes, los indígenas en la historiografia andina: análisis y propuestas”, Anuario del IEHS, 15(2000), p. 87-100.

QUARLERI, L. Rebelión y guerra en las fronteras del Plata: guaraníes, jesuitas e imperios coloniales. Buenos Aires: Fondo de Cultura Económica, 2009. 
RESENDE, M. Gentios brasilicos. Índios coloniais em Minas Gerais setecentista, 2003. Tese (Doutorado em História) - Programa de Pós-Graduação em História, Universidade Estadual de Campinas, Campinas, 2003.

SOARES, M. Devotos da cor. Rio de Janeiro: Civilização Brasileira, 2000.

SPALDING, K. “¿Quiénes son los indios?” In: De indio a campesino. Lima: Instituto de Estudios Peruanos, 1974.

SILVA, I. Vilas de Índios no Ceará Grande: dinâmicas locais sob o Diretório Pombalino. Campinas, SP: Pontes, 2006.

SILVA, M. Cultura no Brasil colônia. Petrópolis, RJ: Vozes, 1981.

TEIXEIRA, I. Mecenato pombalino e poesia neoclássica: Basilio da Gama e a poética do encômio. São Paulo: EDUSP, 1999.

WITTMANN, L. Flautas e maracás: música nas aldeias jesuíticas da América Portuguesa (séculos XVI e XVII), 2011. Tese (Doutorado em História) - Programa de Pós-Graduação em História, Universidade Estadual de Campinas, Campinas, 2011.

\section{Notas}

1 Regimento do Governador Geral Tomé de Souza, 17/12/1548, parágrafo 23. Arquivo Histórico Ultramarino (doravante citado como AHU), Lisboa, cód. 112, fls. 1-9. Este artigo foi baseado fundamentalmente em fontes primárias publicadas e manuscritas. As publicadas em forma de livro, como relatos de jesuítas e de viajantes, foram incluídas na bibliografia por serem de fácil localização. Já no caso das demais, optei por indicá-las em nota de rodapé, de modo a simplificar a sua identificação.

2 Sobre o estatuto dos índios na sociedade colonial, veja-se: Spalding (1974), Boccara (2000), Poloni-Simard (2000).

3 Há uma vasta bibliografia sobre o reformismo ibérico e sua relação com os índios. Para uma visão geral das políticas indigenistas no Império espanhol na segunda metade do século XVIII, veja-se: Garcia (2011). As reformas pombalinas têm sido objeto de um interesse renovado na historiografia. Entre os trabalhos que foram importantes para o desenvolvimento deste campo, podemos citar: GARCIA, 2009; RESENDE, 2003; DOMINGUES, 2000; LOPES, 2015; SILVA, 2006; APOLINÁRIO, 2006.

${ }^{4} \mathrm{~A}$ população que habitava as missões tinha uma origem variada. Havia guaranis, mas também uma significativa presença de outros grupos, como guenoas, minuanos, charruas, etc. A documentação sobre o período e o espaço analisados, porém, utiliza apenas o termo guarani.

5 CARDIEL, José. “Breve relación de las Misiones del Paraguay” [1770]. In: HERNANDÉZ, 1913, vol. II, p. 557.

6 Idem, p. 557.

7 Capítulo del informe que D. Manuel Antonio de la Torre, Obispo de Paraguay, dio al Rey sobre una visita a las Misiones de los PP. Jesuitas. Real Academia de la Historia - Colección Mata Linares. Tomo VIII, 9/1663, fl.131. 
${ }^{8}$ Registro de uma instrução dada pelo Senhor Brigadeiro Governador de como se há de reger o novo recolhimento. Vila Nova dos Anjos, 2 de fevereiro de 1778, pp.31-32; Registro de uma portaria do senhor brigadeiro governador. Vila Nova dos Anjos, 30 de setembro de 1776, p.26; Registro de umas ordens que o senhor brigadeiro governador desta capitania foi servido dar para se observarem na escola desta vila. Vila Nova dos Anjos, 11 de agosto de 1777, pp.26-27. In: Os índios D’Aldeia dos Anjos: Gravataí século XVIII / Arquivo Histórico do Rio Grande do Sul. Porto Alegre: EST, 1990.

${ }^{9}$ Registro de uma instrução dada pelo Senhor Brigadeiro Governador de como se há de reger o novo recolhimento. Vila Nova dos Anjos, 2 de fevereiro de 1778. Parágrafos $5^{\circ}$ e $6 .^{\circ}$ In: Os índios D'Aldeia dos Anjos..., op. cit., p.31.

10 Registro de umas ordens que o senhor brigadeiro governador desta capitania foi servido dar para se observarem na escola desta vila. Vila Nova dos Anjos, 11 de agosto de 1777. In: Os índios D’Aldeia dos Anjos..., op. cit., pp.26-27.

1 Diretório, parágrafo 7. In: ALMEIDA, 1997.

${ }^{12}$ Carta do vice-rei, Marquês do Lavradio, ao governador do Rio Grande, José Marcelino de Figueiredo. Rio de Janeiro, 14 de março de 1771. Arquivo Nacional - Rio de Janeiro (doravante citado como ANRJ)/AP-41 A, microfilme 024-97, RD2.52.

${ }^{13}$ Carta de Bernardo José Pereira, sem lugar, data, nem destinatário, com informações acerca dos índios guaranis do Rio Grande do Sul. Biblioteca Nacional - Rio de Janeiro (doravante citado como BNRJ)/MS 7,3,48.

${ }^{14}$ Ofício do Conde da Cunha a Francisco Xavier de Mendonça Furtado, acerca dos inconvenientes que resultam da persistência dos índios em Viamão, arruinando todas as estâncias daqueles distritos. Rio de Janeiro, 10 de setembro de 1766. Instituto Histórico e Geográfico Brasileiro Arq. 1.1.29 p. 126.

15 Ofício do [vice-rei do Estado do Brasil], conde da Cunha, [D. Antônio Álvares da Cunha], ao [secretário de estado da Marinha e Ultramar], Francisco Xavier de Mendonça Furtado, remetendo ofício do governador e capitão-general do Rio Grande de São Pedro, coronel José Custódio de Sá e Faria, comunicando as grandes despesas feitas com a manutenção dos índios das missões, alojados na região de Viamão, que faziam grande consumo de reses de gado e de farinha de mandioca. Totalizavam cerca de 2.397 e provocavam desordens e roubos nas estâncias vizinhas. Informa que o governador de Buenos Aires, D. Pedro de Cevallos, postulava a restituição desses indígenas aos castelhanos. Rio de janeiro, 19 de setembro de 1764. AHU, Rio de Janeiro, cx. 72, d. 6612.

${ }^{16}$ Cópia das instruções que formalizou o senhor brigadeiro governador para auxílio do regime do Comandante da Povoação de Nossa Senhora dos Anjos o Tenente da Cavalaria Auxiliar Antônio José Machado. Rio Grande, 14 de janeiro de 1784. In: Os índios d'Aldeia dos Anjos..., op. cit., p.76.

17 Cópia de uma carta escrita pelo oficial das ordens do senhor brigadeiro governador do continente ao capitão comandante dessa vila em que fala respeito ao regime que deve obrar dito comandante com o recolhimento e escola destes índios. Vila dos Anjos, 26 de setembro de 1780. In: Os índios D'Aldeia dos Anjos..., op. cit., p. 37.

${ }^{18}$ Carta do vice-rei, Marquês do Lavradio, ao Governador Antônio de Veiga de Andrade na data de 14 de março de 1771. ANRJ - Fundo Marquês do Lavradio, microfilme 024-97, RD 2.94v. 
19 Processo de Gênese do Padre José Inácio da Silva Pereira, 1781. Arquivo da Cúria do Rio de Janeiro, Letra J. Cx. 1780-1789; Cx.1; Maço 38 - N 14. Agradeço a Protásio Paulo Langer por ter me cedido o documento.

20 Relação dos gêneros com que assistiu Francisco Pereira Pinto para fardar um cacique e demais rapazes das famílias guaranis que se remeteram para a capital do Rio de Janeiro por ordem do Snr. Marquês Vice-Rei. 08 de maio de 1773. Arquivo Histórico do Rio Grande do Sul (doravante citado como AHRGS)/Fazenda, 1773, Diversos Papéis. Maço 18, Lata 04.

21Portaria para o Desembargador Provedor da Fazenda Real mandar assistir com todo o necessário aos índios que vieram do Continente do Rio Grande. Rio de Janeiro, 13 de setembro de 1773. ANRJ - cód.73, vol.08. fl.65v.

22 Informe sobre la decadencia de los pueblos de misiones, por don Carlos José de Añasco. Ciudad de las Corrientes, 26 de marzo de 1778. BNRJ - Coleção de Angelis, MS-508 (26), doc.758.

${ }^{23}$ Sobre o funcionamento das disputas por prestígio e distinção no Antigo Regime, veja-se: Elias (2001). Para a apropriação desta lógica pelos grupos subalternos, veja-se: Soares (2000).

${ }^{24}$ Portaria para o Desembargador Provedor da Fazenda Real mandar dar o vestuário, que consta de um papel, ao índio Miguel Pinto Carneiro. Rio de Janeiro, 13 de julho de 1773. ANRJ - cód.73, vol.08. fl.50.

${ }^{25}$ Portaria para o Desembargador Provedor da Fazenda Real mandar dar ao índio Cristóvão da Costa Freire o conteúdo de uma lista. Rio de Janeiro, 28 de janeiro de 1774. ANRJ - cód.73, vol.08. fl.113.

26 De José Marcelino de Figueiredo para Luiz de Vasconcelos e Souza. Porto Alegre, 24 de janeiro de 1780. ANRJ - cód.104, vol.2. fl.36.

${ }_{27}$ Portaria do governador José Marcelino de Figueiredo. Vila Nova dos Anjos, 8 de dezembro de 1779. AHRGS - Fazenda, 1779. Portarias do Governador. Maço 22, Lata 5.

${ }^{28}$ Portaria para o Desembargador Provedor da Fazenda Real mandar dar os gêneros conteúdos em uma relação para os dois índios do Rio Grande Pascoal Baylão e Nicolau da Costa Guimarães. Rio de Janeiro, 2 de abril de 1773 e Portaria para o Desembargador Provedor da Fazenda Real, mandar dar o vestuário, que consta de uma relação a cada um dos dois índios nela declarados. Rio de Janeiro, 13 de julho de 1773. ANRJ - cód.73, vol.08. respectivamente fl.24v e fl.50.

29 Processo de Gênese do Padre José Inácio da Silva Pereira, 1781. Arquivo da Cúria do Rio de Janeiro, Letra J. Cx. 1780-1789; Cx.1; Maço 38 - No 14.

${ }^{30}$ Bettamio, Sebastião Francisco. "Noticia particular do Continente do Rio Grande do Sul” [1780]. In: Revista do Instituto Histórico e Geográfico Brasileiro. Tomo 31, 3 trimestre de 1858. 2ª. ed. 1930. pp.222-223.

31 Idem, p. 231.

32 Carta do vice-rei, Marquês do Lavradio, ao governador do Rio Grande, José Marcelino de Figueiredo. Rio de Janeiro, 14 de março de 1771. ANRJ - AP-41 A, microfilme 024-97, RD2.52.

${ }^{33}$ Ofício do Vice-rei Luiz de Vasconcelos e Souza, com cópia da relação instrutiva e circunstanciada, para ser entregue ao seu sucessor, na qual mostra o estado em que deixa os negócios mais importantes do seu governo; sendo um deles a demarcação de limites da América meridional. Rio de Janeiro, 20 de agosto de 1789. In: Revista do Instituto Histórico e Geográfico Brasileiro, n.13, abril de 1842. p.159. 
${ }^{34}$ Bettamio, Sebastião Francisco, op. cit., p.223.

${ }^{35}$ Requerimento dos donos das fazendas de Viamão ao rei, solicitando ordem para que o vicerei do estado do Brasil mande transportar os índios para o norte do Rio Tramandaí, a fim de povoarem aquelas terras e criarem gado. Rio Grande de São Pedro, ant. 5 de dezembro de 1768. AHU, Rio Grande do Sul, cx. 2, d. 159

${ }^{36}$ Carta dos oficiais da Câmara do Rio Grande de São Pedro ao rei, solicitando o aldeamento dos índios Tapes em outras regiões, devido aos roubos de gado feitos pelos índios, que tiram o sossego e a paz dos moradores dos Campos de Viamão. Viamão, 23 de setembro de 1771. AHU, Rio Grande do Sul, cx. 2, d. 171.

${ }^{37}$ Registro de uma carta do Ilmo. e Exmo. Senhor Marquês Vice-Rei do Estado escrita ao Senhor Brigadeiro Governador José Marcelino de Figueiredo e cópia de outra escrita à câmara deste continente respeito arrematação do açougue dessa vila. Rio de Janeiro, 11 de junho de 1778. In: Os índios d'Aldeia dos Anjos..., op. cit., pp.35-36.

38 Instrução do Marquês de Pombal para o Marquês do Lavradio. Lisboa, 9 de julho de 1774. In: MENDONÇA, 1989. p. 605.

\section{Declaração de financiamento}

A pesquisa que resultou neste artigo contou com o financiamento do CNPq (processo 310956/2018-8) e da FAPERJ (E-26/203.226).

Elisa Frühauf Garcia é Doutora em história pela Universidade Federal Fluminense (2007), onde é professora de história da América colonial desde 2009. Atua também no programa de pósgraduação em história da mesma instituição (PPGH/UFF), orientando teses e dissertações sobre as relações entre as populações nativas e os impérios coloniais europeus. Realizou estágios de pós-doutorado na Universidade Estadual de Campinas (2007-2009) e no Consejo Superior de Investigaciones Científicas/CSIC-Madrid (2015). É membro do grupo de pesquisa Companhia das Índias, da Red Columnaria (Polo Brasil) e pesquisadora do CNPq. Sua tese, As diversas formas de ser índio: políticas indígenas e políticas indigenistas no extremo sul da América portuguesa, foi premiada pelo Arquivo Nacional e publicada em 2009. É autora de artigos em livros e revistas sobre a história indígena nos impérios ibéricos, especialmente nas áreas de fronteira na bacia do Rio da Prata. Seus interesses vinculam-se à história das populações nativas e temas correlatos, atualmente com ênfase nas mulheres indígenas. 